\title{
Analisis Kegagalan Pada Komponen Poros Pompa Industri
}

\section{Failure Analysis on Industrial Shaft Pump Component}

\author{
Restyarno Agung Nugroho ${ }^{*}$, Priyo Tri Iswanto ${ }^{2}$ \\ ${ }^{1,2}$ Departemen Teknik Mesin dan Industri, Fakultas Teknik, Universitas Gadjah Mada
}

\begin{tabular}{|c|c|}
\hline ARTICLE INFO & ABSTRACT \\
\hline Article history: & $\begin{array}{l}\text { Pumps are very important industrial equipment in the petroleum industry. The } \\
\text { component that often fails is the pump shaft. Therefore, it is necessary to conduct a }\end{array}$ \\
\hline $\begin{array}{l}\text { DOI: } \\
\text { 10.30595/pspfs.v1i.135 }\end{array}$ & $\begin{array}{l}\text { failure analysis of this component to determine the mode/type of failure and how it } \\
\text { occurred. This study used Scanning Electron Microscope (SEM), metallographic } \\
\text { test, chemical composition test, and Brinell hardness test with the standard }\end{array}$ \\
\hline $\begin{array}{l}\text { Submitted: } \\
\text { June } 26,2021\end{array}$ & $\begin{array}{l}\text { UNSS } 42000 \text { material. Fatigue test to determine the fatigue limit of the shaft with a } \\
\text { rotary bending fatigue test. The failure model that occurred was fatigue failure } \\
\text { characterized by initial cracks, crack growth, ratchet marks, sudden fracture areas. } \\
\text { Based on the comparison between the test results of chemical composition and }\end{array}$ \\
\hline $\begin{array}{l}\text { Accepted: } \\
\text { July } 10,2021\end{array}$ & $\begin{array}{l}\text { mechanical properties of the material, the drive shaft pump material was suitable for } \\
\text { the UNS S42000 material. }\end{array}$ \\
\hline $\begin{array}{l}\text { Published: } \\
\text { Oct } 31,2021\end{array}$ & $\begin{array}{l}\text { This work is licensed under a Creative Commons Attribution } 4.0 \text { International } \\
\text { License. }\end{array}$ \\
\hline & (c) \\
\hline Keywords: & \\
\hline $\begin{array}{l}\text { Shaft, Pump, Centrifugal, } \\
\text { Fatigue, UNS S42000 }\end{array}$ & \\
\hline \multicolumn{2}{|c|}{$\begin{array}{l}\text { Corresponding Author: } \\
\text { Restyarno Agung Nugroho } \\
\text { Departemen Teknik Mesin dan Industri, Fakultas Teknik, Universitas Gadjah Mada } \\
\text { Jl. Grafika No. 2, Kompleks UGM, Yogyakarta 55281, Indonesia } \\
\text { Email: restyarno@gmail.com }\end{array}$} \\
\hline
\end{tabular}

\section{PENDAHULUAN}

Dunia modern ini, kebutuhan akan sumber energi, terutama energi minyak bumi, adalah kebutuhan yang sangat besar. Atas dasar tersebut, maka produksi sumber energi minyak bumi, harus dilakukan sebaik mungkin dan seefisien mungkin agar suplai produksi minyak bumi dapat disalurkan secepat dan sebaik mungkin. Berbagai cara dilakukan agar dapat menghasilkan minyak bumi sebaik dan sebanyak mungkin dengan cara yang mudah dan efisien. Berbagai peralatanpun digunakan, seperti penggunaan mesin pompa dan kompresor. Pompa yang pertama kali diciptakan manusia adalah sistem pompa bernama Shadoof yang diciptakan oleh bangsa mesin pada tahun 2000 SM (Pumps, 2009). Pompa merupakan peralatan industri yang sangat penting dalam industri minyak bumi. Keduanya memiliki peran penting dalam proses produksi di industri minyak bumi. Komponen pompa jika mengalami kegagalan akan menjadikan kegiatan produksi di industri minyak bumi terhambat dan merugikan perusahaan. Kerusakan yang terjadi pada komponen-komponen pompa adalah sebuah kerusakan yang tidak biasa. Hal ini karena umur komponenkomponen tersebut masih dapat dianggap sebagai komponen yang baru. Oleh karena itu. perlu dilakukan kajian analisis kerusakan (failure analysis) terhadap komponen-komponen tersebut. Hal ini dilakukan untuk mengetahui apa mode/jenis kerusakan yang terjadi dan bagaimana kerusakan itu terjadi. Uji yang sudah dilakukan terhadap komponen tersebut adalah uji tarik, uji impak, uji kekerasan, uji komposisi kimia, uji SEM, uji struktur mikro, dan uji korosi untuk mengetahui laju korosi dari material tersebut. 


\section{METODE PENELITIAN}

Apabila suatu benda mengalami kegagalan, perlu dilakukan pelacakan terhadap kinerja benda tersebut sebelum terjadi kegagalan. Kegiatan menganalisa suatu kegagalan dalam rangka untuk mengetahui penyebab terjadinya kegagalan tersebut merupakan suatu proses analisas kegagalan. Kegagalan yang terjadi pada suatu benda bisa berasal dari tahap manufakturing, pembuatan, perakitan, atau pengoperasian yang tidak sesuai dengan desain (Muzakir, 2017). Terdapat beberapa tahapan dalam suatu analisis kegagalan hingga ditemukan penyebab dari kegagalan suatu benda. Tahapan tersebut yaitu pengumpulan informasi, pengujian material benda yang mengalami kerusakan, dan menganalisis kemungkinan terjadinya kegagalan. Berikut beberapa investigasi utama dan sering dilakukan dalam melakukan analisa kegagalan :

\section{Faktografi}

Pengujian SEM bertujuan untuk pengamatan fraktografi, yaitu untuk mengetahui profil permukaan patahan secara mikro. SEM merupakan jenis mikroskop elektron yang mencitrakan permukaan sampel oleh pemindaian dengan pancaran tinggi elektron. Sampel yang diambil untuk pengujian SEM ini adalah penampang poros pompa industri yang patah, disesuaikan dengan kapasitas chamber alat uji SEM. Pengujian ini dilakukan di Laboratorium Penelitian dan Pengujian AAU Yogyakarta.

\section{Pengujian metalografi}

Pengujian metalografi dilakukan untuk mengetahui struktur mikro yang terdapat pada poros pompa industri yang patah untuk kemudian dibandingkan dengan struktur mikro baja than karat AISI 316 sesuai ASM Handbook Vol. 9 (Metallography and Microstructur). Persiapan spesimen meliputi pemotongan spesimen yang diambil dari sisa patahan poros, grinding dan polishing agar permukaan spesimen rata, dan proses etsa dengan $\mathrm{HCl}, \mathrm{HNO}$, dan air dalam komposisi setara (ASM International, 1985). Pengujian ini dilakukan di laboratorium bahan Teknik DTMI UGM.

\section{Pengujian komposisi kimia}

Pengujian komposisi kimia bertujuan untuk mengetahui persentase unsur-unsur yang menyusun sebuah material. Pengujian ini tidak membutuhkan spesimen berukuran khusus, serta tidak ada perlakuan khusus sebelumnya. Sampel dari spesimen akan dibersihkan dari zat pengotor, lalu alat uji akan menembakkan sinar laser pada permukaan sampel. Alat uji akan mendeteksi kandungan unsur dalam material dan memberikan informasi terkait hal tersebut beserta persentase dari unsur-unsur tersebut.

\section{Pengujian kekerasan}

Metode uji kekerasan yang dipergunakan dalam penelitian ini adalah metode Brinnel di mana indentor bola baja ditekan dengan beban tetap ke permukaan suatu bahan. Pengujian kekerasan dilakukan untuk mengetahui ketahanan bahan terhadap indentasi permukaaan dari indentor atau goresan yang diterima. Ketika kesetimbangan tercapai, beban dan indentor ditarik, dan diameter cekungan yang terbentuk (diameter impresi) pada permukaan diukur menggunakan mikroskop dengan skala mikrometer. Kekerasan Brinell dinyatakan sebagai angka kekerasan Brinell (BHN), yaitu rasio dari beban indentor $\mathrm{F}$ ke area cekung permukaan bekas identasi. Nilai BHN dapat diketahui dari persamaan berikut (Askeland, Fulay, \& Wright, 2010)

$$
B H N=\frac{2 F}{\pi D\left(D-\sqrt{D^{2}-D_{i}^{2}}\right.}
$$

dengan,

BHN : angka kekerasan Brinell $\left(\mathrm{kg} / \mathrm{mm}^{2}\right)$,

F : beban identasi $(\mathrm{kg})$,

D : diameter bola identor $(\mathrm{mm})$,

$\mathrm{D}_{\mathrm{i}} \quad$ : diameter impresi $(\mathrm{mm})$

\section{Pengujian laju korosi}

Uji korosi dilakukan dengan metode polarisasi potensiodinamik menggunakan sel tiga elektroda pada Gambar 1 yang dihubungkan dengan potensiostat Autolab VersaSTAT 4. Uji korosi dilakukan untuk mengetahui seberapa besar laju korosi yang terjadi pada material. Parameter yang digunakan dalam pengujian ini antara lain scan rate sebesar 2 $\mathrm{mV} / \mathrm{s}$ dan air sungai sebagai media larutan. Elektroda kerja yang diukur laju korosinya adalah spesimen poros pompa industri dengan material SUS 420 (UNS S42000). Elektroda acuan yang digunakan pada pengujian sel elektrokimia adalah elektroda kalomel jenuh (Saturated Calomel Electrode). Antara elektroda kerja dan elektroda acuan diberi tegangan, sehingga mempercepat terjadinya korosi. Saat terjadi korosi, arus dihasilkan dari elektroda kerja yang kemudian akan dialirkan ke luar larutan oleh elektroda pembantu yang terbuat dari karbon. Arus yang dialirkan ini 
akan terukur oleh potensiostat, maka akan didapatkan hasil data berupa kurva Tafel dan besarnya rapat arus ( $i_{\text {corr }}$ ). Penentuan harga rapat arus korosi secara tepat sangat diperlukan, karena rapat arus korosi sebanding dengan laju korosi suatu logam dalam lingkungannya. Hal ini sesuai dengan persamaan laju korosi (Jones, 1991) dalam mils (0,001 in) per year (mpy) seperti ditunjukan pada persamaan:

dengan,

$$
C R=0,129 \times \frac{E w \times i_{\text {corr }}}{A \times D}
$$

CR : corrosion rate (laju korosi) dalam mpy

A : luas permukaan specimen $\left(\mathrm{cm}^{2}\right)$

$\mathrm{I}_{\text {corr }} \quad$ : rapat arus korosi $\left(\mu \mathrm{A} / \mathrm{cm}^{2}\right)$

$\mathrm{E}_{\mathrm{w}} \quad$ : berat ekuivalen $(\mathrm{gram} / \mathrm{mol})$

D : berat jenis sampel $\left(\mathrm{gr} / \mathrm{cm}^{3}\right)$

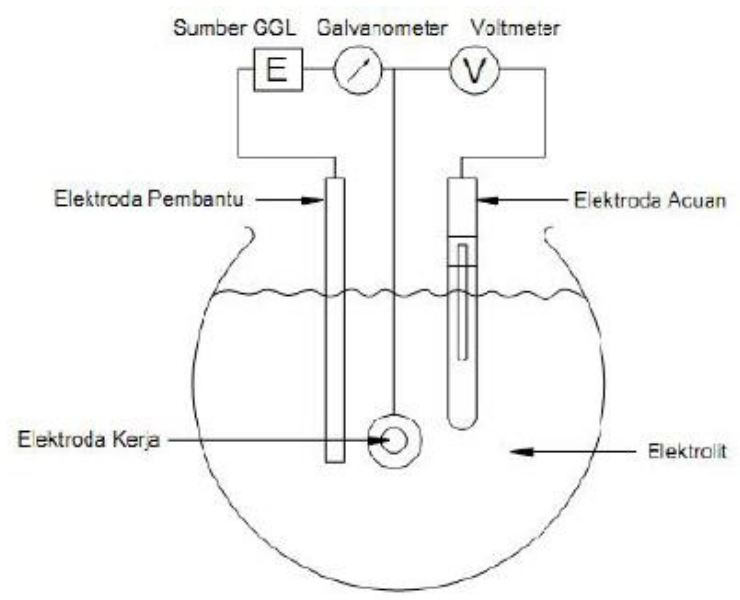

Gambar 1. Skema sel tiga elektroda uji korosi (Trethewey \& Chamberlain, 1991)

\section{HASIL DAN PEMBAHASAN}

\section{Pengujian Scanning Electron Microscope}

Pengamatan Scanning Electron Microscope dilakukan untuk mencari bukti penyebab kegagalan dan mengamati pola patahan yang terbentuk setelah poros mengalami kegagalan. Pengamatan dilakukan dengan menggunakan Scanning Electron Microscope (SEM). Dari Gambar 2 (a) dan (b) menunjukkan adanya jejak garis yang berasal dari bagian terluar dan merambat ke dalam yang mana menjadi petunjuk sebagai daerah initial crack. Pada Gambar 3 juga menunjukkan adanya ratchet marks. Ratchet marks merupakan titik - titik inisiasi pada kegagalan fatigue. drive shaft pump patah di daerah ulir di mana daerah tersebut terjadi konsentrasi tegangan. Bagian ulir ini tersambung dengan housing bearing dimana terdapat rangkaian bearing dari motor dan coupling yang berfungsi sebagai support dari poros pompa industri. Dari Gambar 2 (b) juga dapat dilihat ada dua daerah kegagalan fatik, yaitu daerah yang menunjukkan pertumbuhan retak yang lambat dengan penampakan permukaan yang halus (daerah sisi kanan penampang) dan daerah patah mendadak dengan penampakan permukaan kasar (daerah sisi kiri dan atas penampang). Adanya initial crack, pertumbuhan retak yang lambat dan daerah patah mendadak menunjukan kegagalan yang terjadi adalah kegagalan fatik. Ciri - ciri patah fatik lainnya adalah adanya striasi yang mana tidak terlihat pada pengamatan menggunakan Scanning Electron Microscope (SEM). Tidak semua material yang mengalami patah fatik ditemukan adanya striasi (ASTM, 1965). Striasi akan tampak jelas pada pure metals dan alumunium. Beberapa literatur menyebutkan bahwa setiap striasi menunjukkan satu siklus pembebanan. Striasi menjalar sesuai dengan arah pembebanan. 

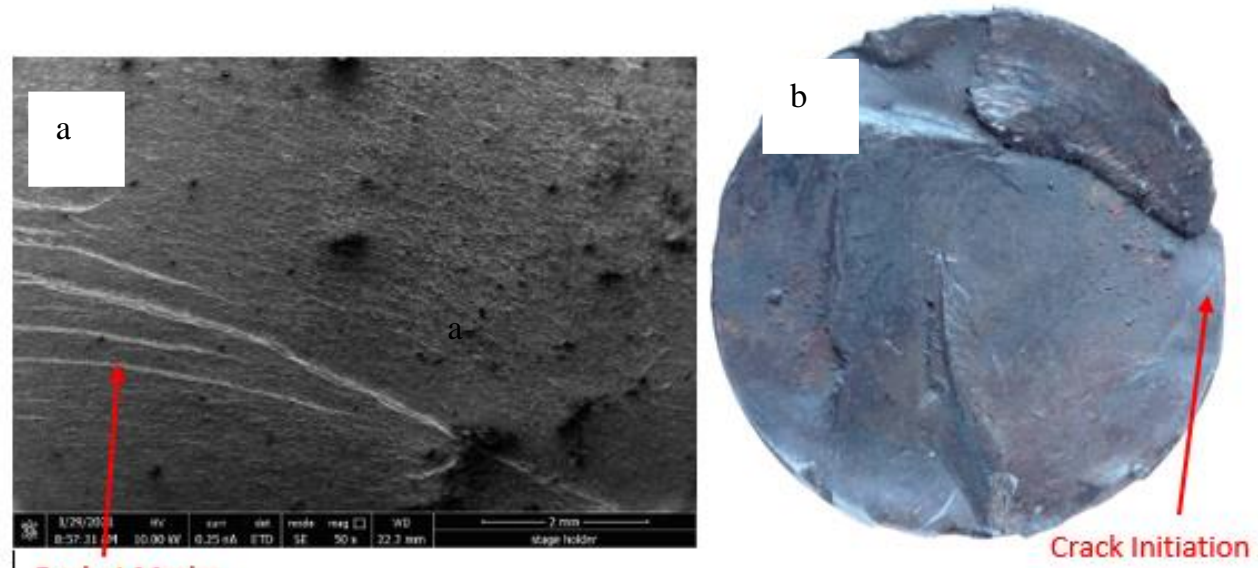

Gambar 2. a Hasil Pengujian Scanning Electron Microscope pembesaran 50x pada initial crack.

$\mathrm{b}$ Penampang patahan drive shaft pump

\section{Pengujian metalografi}

Pengamatan metalografi dilakukan untuk mengamati sruktur mikro pada material drive shaft pump berupa SUS 420. Dari pemeriksaan struktur mikro nanti akan didapatkan fasa pada material poros tersebut. Pengamatan metalografi menggunakan cairan etsa $\mathrm{HCl}, \mathrm{HNO} 3$, dan air dalam komposisi setara dengan waktu 30-40 detik. Hasil struktur mikro spesimen drive shaft pump P-61-221-D dengan pembesaran 500x ditunjukkan pada Gambar 3 (a) dan hasil pengamatan mikro stainless steel 420 / ASTM A480 sesuai ASM Handbook volume 9 ditunjukkan pada Gambar 3.2 (b) (ASM International,1985). Pada Gambar 3 (a) menunjukkan bahwa poros pompa industri memiliki fasa martensit seperti jarum, ferit yang berwarna terang, dan perlit yang berwarna gelap. Jika dari pengujian komposisi kimia dan kekerasan tidak ada perbedaan signifikan dengan standar bahan stainless steel 420 / ASTM A480, maka dapat disimpulkan bahan poros adalah sama sesuai standar.

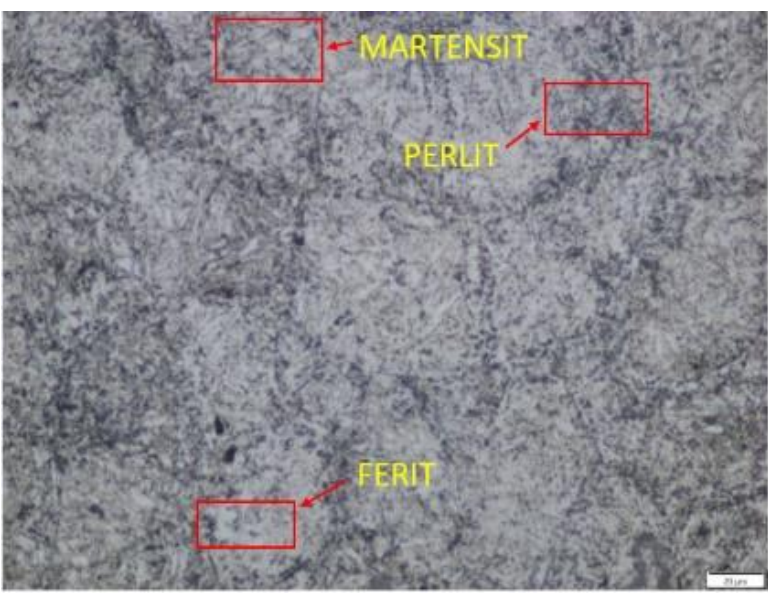

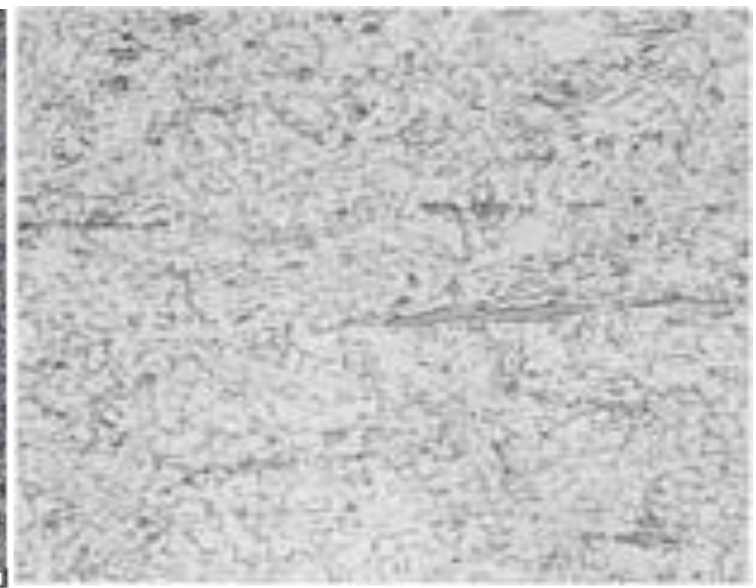

$\mathrm{b}$

Gambar 3 Hasil Metalografi a). Poros pompa industri dengan pembesaran 500x, b) Stainless steel 420 sesuai ASM Handbook volume 9 dengan pembesaran 400x

\section{Pengujian komposisi kimia}

Hasil pengujian komposisi kimia poros pompa industri dicocokkan dan dibandingkan dengan komposisi kimia standar komposisi kimia pada Handbook of Comparative World Steel Standard (ASTM International, 2004). Hasil perbandingan dapat dilihat pada tabel 1 . 
Tabel 1. Hasil uji komposisi kimia

\begin{tabular}{cccccccccc}
\hline \multicolumn{2}{c}{ Komposisi kimia } & C & Mn & Si & P & S & Cr & Ni & Mo \\
\hline $\begin{array}{c}\text { UNS S42000 } \\
(\%)\end{array}$ & Min & 0,15 & - & - & - & - & 12.0 & - & - \\
& Max & - & 1.0 & 1.0 & 0.04 & 0.03 & 14.0 & 0,75 & 0,5 \\
$\begin{array}{c}\text { Komposisi sampel } \\
(\%)\end{array}$ & 0,237 & 0,6471 & 0,2911 & 0,0233 & 0,0015 & 13,2580 & 0,8043 & 0,8994 \\
\hline
\end{tabular}

Setelah dicocokkan dengan komposisi kimia standar Martensitic Stainless Steel pada Handbook of Comparative World Steel Standard, poros pompa industri yang mengalami kegagalan memiliki komposisi kimia yang tidak berbeda jauh hal tersebut menunjukkan bahwa material baja tersebut termasuk ke dalam ASTM A480 / UNS S42000. Persentase unsur $\mathrm{C}$ dari hasil uji lebih tinggi apabila dibandingkan dengan standar minimum. Hal ini menunjukkan angka kekerasan poros pompa industri yang lebih tinggi dibandingkan angka maksimum dalam standar dan membuat material dari poros pompa industri masih kurang dari $0,25 \%$ yaitu baja karbon rendah. Terdapat unsur Mo yang melebihi standar, di mana unsur Mo berfungsi untuk meningkatkan hardenability dan kekuatan (Avner, 1974).

\section{Pengujian kekerasan}

Dalam penelitian analisa kegagalan ini selain dilihat dari aspek metalurgi, tentu juga dibutuhkan data - data dari aspek mekanik untuk menguatkan hipotesa dalam penelitian ini. Salah satu data mekanik yang, diperlukan adalah data kekerasan dari material tersebut. Untuk itu perlu dilakukan pengujian kekerasan pada potongan poros pompa industri yang mengalami kegagalan. Pengujian kekerasan dilakukan menggunakan uji kekerasan Brinell untuk didapatkan nilai kekerasan angka kekerasan Brinnel (BHN). Dari hasil perhitungan didapatkan nilai kekerasan brinnel yaitu sebesar 177 BHN. Sedangkan berdasar standar ASTM International pada handbook of comparative world steel standard nilai kekerasan UNS 42000 maksimal 217 BHN (ASTM International, 2004). Hal ini menunjukkan bahwa material poros pompa industri masih termasuk ke dalam UNS 42000 yang tergolong ke dalam martensit stainless steel.

\section{Pengujian laju korosi}

Pengujian laju korosi dilakukan pada media larutan air sungai. Beberapa faktor yang mempengaruhi besarnya nilai korosi adalah $\mathrm{I}_{\mathrm{corr}}, \mathrm{E}_{\mathrm{w}}$, dan densitas material. Icorr adalah rapat arus korosi, sedangkan equivalent weight adalah rata-rata berat atom pada valensi ion pada unsur paduan utama (Barker \& Walsh, 1991). Hasil pengujian laju korosi menggunakan metode polarisasi potensiodinamik mendapat mendapat nilai $i_{c o r r}$ pada penelitian, kemudian dilakukan perhitungan laju korosi dan menunjukkan laju korosi spesimen poros pompa industri UNS S42000 pada media air sungai sangat rendah yaitu sebesar 0,3507 mpy. Kandungan Kromium yang tinggi sebesar 13,258 yang membuat material UNS S42000 tahan terhadap korosi. Pentingnya kandungan kromium yang tinggi pada poros pompa karena kondisi lingkungan kerja dari pompa yang korosif yaitu pompa berada di dalam sungai dan digunakan untuk memompa air sungai. Laju korosi yang rendah pada material UNS S42000, maka korosi tidak menjadi penyebab terjadinya kegagalan pompa P-61-221-D.

\section{KESIMPULAN}

Setelah melakukan pengujian pada komponen poros pompa industri, model kegagalan yang terjadi yaitu kegagalan fatik atau poros mengalami kelelahan karena fluktuasi beban yang berulang-ulang, yang ditandai dengan adanya initial crack, ratchet mark, pertumbuhan retak yang lambat dan daerah patah mendadak pada pengamatan scanning electron microscope. Sifat mekanis dan komposisi kimia dari material poros pompa industri sesuai dengan karakteristik yang dimiliki UNS S42000. Laju korosi dari material poros pompa industri sangat kecil sehingga korosi tidak menjadi penyebab terjadinya kegagalan.

\section{DAFTAR PUSTAKA}

Askeland, D. R., Fulay, P. P., \& Wright, W. J. (2010). The Science and Engineering of Materials (Sixth ed.). USA: Cengage Learning.

ASM. (2004). Metallography and Microstructure (Vol. ASM Handbook Vol. 9). ASM International.

ASM International. (1985). Metallography and Microstructure (Vol. 9). United State America: ASM International.

ASTM. (1965). Advances in the Technology of Stainless Steels and Related Alloy. Philadelphia: American Society for Testing and Materials.

ASTM International. (2004). Handbook of Comparative World Steel Standards. (J. E. Bringas, Ed.) USA. 
Avner, S. H. (1974). Introduction to physical metallurgy. New York: McGraw-hill.

Barker, D., \& Walsh, F. C. (1991). Application of Faraday's Laws of Electrolysis in Metal Finishing. 158-162.

Bhandari, V. B. (2010). Design of Machine Elements. USA: McGraw-Hill.

Jones, D. A. (1991). Principles and Prevention of Corrosion. New York: McMillan Publising Company.

Muzakir, I. (2017, July 6). Material Engineering by Rangga Agung's Team. Retrieved September 4, 2020, from https://materialengineeringranggaagung.wordpress.com/2017/07/06/failure-analysis-analisis-kegagalan/

Pumps, W. (2009). A Brief History of Pumps. Elsevier.

Trethewey, K. R., \& Chamberlain, J. (1991). Korosi Untuk Mahasiswa Sains dan Rekayasa. Jakarta: PT. Gramedia Pustaka utama. 